\title{
Single-Fed Broadband CP Bidirectional Antenna with Double-Layer Diagonally Aligned Plates for Universal UHF-RFID Applications
}

\author{
Sitthichai Dentri, ${ }^{1}$ Khanet Pookkapund, ${ }^{2}$ Bancha Luadang, ${ }^{3}$ Prayoot Akkaraekthalin, ${ }^{4}$ \\ and Chuwong Phongcharoenpanich $\mathbb{D}^{2}$ \\ ${ }^{1}$ Research Center of Innovation Digital and Electromagnetic Technology (iDEMT), College of Industrial Technology, \\ King Mongkut's University of Technology North Bangkok, Bangkok, Thailand \\ ${ }^{2}$ Faculty of Engineering, King Mongkut's Institute of Technology Ladkrabang, Bangkok, Thailand \\ ${ }^{3}$ Faculty of Engineering, Rajamangala University of Technology Rattanakosin, Nakhon Pathom, Thailand \\ ${ }^{4}$ Department of Electrical and Computer Engineering, Faculty of Engineering, \\ King Mongkut's University of Technology North Bangkok, Bangkok, Thailand \\ Correspondence should be addressed to Chuwong Phongcharoenpanich; chuwong.ph@kmitl.ac.th
}

Received 1 July 2020; Revised 3 September 2020; Accepted 22 September 2020; Published 8 October 2020

Academic Editor: Rodolfo Araneo

Copyright (c) 2020 Sitthichai Dentri et al. This is an open access article distributed under the Creative Commons Attribution License, which permits unrestricted use, distribution, and reproduction in any medium, provided the original work is properly cited.

\begin{abstract}
This research proposes a single-fed broadband circularly polarized (CP) bidirectional antenna operable in $840-960 \mathrm{MHz}$ frequency band for readers of universal UHF-RFID applications. The proposed antenna is comprised of upper-layer conductor, lower-layer conductor, and wall patches. The upper-layer conductor consists of two diagonally aligned rectangular copper plates with a feeding gap at the center, and the lower-layer conductor is of two diagonally adjoined rectangular plates. The upper- and lower-layer conductors are adjoined with the wall patches. The diagonal alignment technique of the upper- and lower-layer plates was used to realize circular polarization and improve 3-dB axial ratio (AR) bandwidth. The double layers were deployed to improve impedance bandwidth $\left(\left|S_{11}\right|<-10 \mathrm{~dB}\right)$ and achieve bidirectional radiation pattern. The simulated impedance bandwidth and 3-dB AR bandwidth were $772.19-1014.6 \mathrm{MHz}(27.13 \%)$ and $675-1000 \mathrm{MHz}(38.80 \%)$, and the corresponding measured results were $759-1011 \mathrm{MHz}(28.47 \%)$ and $648-1110 \mathrm{MHz}$ (52.55\%). The simulated LHCP/RHCP half-power beamwidth (HPBW), $3-\mathrm{dB}$ AR beamwidth, and gain were $56^{\circ}-90^{\circ} / 54^{\circ}-92^{\circ}, 60^{\circ}-104^{\circ}$, and $4.94-5.89 \mathrm{dBic}$, while the corresponding measured results were $52^{\circ}-98^{\circ} / 62^{\circ}-97^{\circ}, 96^{\circ}-126^{\circ}$, and $4.28-5.72 \mathrm{dBic}$. As a result, the single-fed broadband CP bidirectional antenna is applicable to universal UHF-RFID readers. Besides, the novelty of this research lies in the use of diagonal alignment of conducting plates to achieve circular polarization and wider AR bandwidth.
\end{abstract}

\section{Introduction}

Radio frequency identification (RFID) technology is commonly utilized for wireless multiaccess identification and tracking in logistics, livestock farming, and toll collection $[1,2]$. Ultrahigh frequency (UHF) RFID varies from country to country. The RFID frequency band in China is $840.5-844.5 \mathrm{MHz}, \quad 920-925 \mathrm{MHz}$ in Thailand, and $902-928 \mathrm{MHz}$ in the US. Meanwhile, the Federal Communications Commission's (FCC) universal RFID frequency band is $860-960 \mathrm{MHz}$. RFID reader antennas have to be able to communicate between readers and tags, independent of tag orientation. To satisfy this requirement, $\mathrm{CP}$ antennas are thus necessary $[3,4]$. Meanwhile, bidirectional radiation is ideal for identification and tracking moving objects in a tunnel or on a conveyor belt [5].

Previous research proposed techniques to realize wideband CP antennas [6-14]. In [6], a CP slot antenna was proposed, and the antenna could achieve a fractional $\mathrm{CP}$ bandwidth (FCPBW) over $40 \%$ and $3-\mathrm{dB}$ AR bandwidth of 
$48 \%$. However, the antenna gain was comparably low (4.2 dBic). In [7], a novel broadband CP antenna with square slot was proposed for UHF-RFID applications. The CP antenna achieved impedance bandwidth of $142 \mathrm{MHz}(15.3 \%$ at $931 \mathrm{MHz})$ and 3-dB AR bandwidth of $166 \mathrm{MHz}(17.7 \%$ at $940 \mathrm{MHz}$ ). In [8], a compact CP slot antenna was proposed to improve impedance matching and broadband CP. In [9], a simple rotational symmetric printed bow-tie dipole structure was proposed for frequency-selective polarization antenna (FSPA), and the antenna could achieve impedance bandwidth of $1.9-5.65 \mathrm{GHz}(98.7 \%)$ and $3-\mathrm{dB}$ AR bandwidths of $8.3 \%(2.3-2.5 \mathrm{GHz})$ and $13.3 \%(4.9-5.6 \mathrm{GHz})$. In [10], a novel antenna was proposed to achieve bidirectionally tilted circular polarization. In [11], a CP monopole antenna based on natural boundary conditions was proposed and could achieve $3-\mathrm{dB}$ AR bandwidths of $5.38 \%$ and $2.84 \%$. In [12], a geometrically simple structure for broadband CP applications could achieve very wide impedance bandwidth of $89 \%$ with $82 \%$ CP bandwidth but low antenna gain $(<5 \mathrm{dBic})$. In [13], a compact broadband dual-band CP square slot antenna was proposed for worldwide UHF-RFID handheld readers and L2 and L5 global positioning system (GPS). The proposed antenna achieved impedance bandwidth of $716-1268 \mathrm{MHz}(552 \mathrm{MHz})$ and $3-\mathrm{dB}$ AR bandwidth of $824-1388 \mathrm{MHz}(564 \mathrm{MHz})$. However, the antenna gain was relatively low $(<5 \mathrm{dBic})$. In [14], three low-profile ultra-wideband (UWB) circularly polarized slot antennas were proposed for UWB indoor wireless access. However, the antennas suffered from bulkiness.

This research proposes a single-fed broadband CP bidirectional antenna that efficiently covers the universal UHF-RFID frequency band. The proposed folded antenna is comprised of upper-layer conductor, lower-layer conductor, and wall patches. The upper-layer conductor consists of two diagonally aligned rectangular copper plates with a feeding gap at the center, and the lower-layer conductor is of two diagonally adjoined rectangular plates. The upper- and lower-layer conductors are adjoined with the wall patches.

The organization of the research is as follows: Section 1 is the introduction. Section 2 details the design of the antenna structure. Section 3 deals with the simulation and measurement results, and Section 4 discusses the parametric study analysis. The concluding remarks are provided in Section 5.

\section{Antenna Structure}

Figure 1 illustrates the geometry and parameters of the single-fed broadband CP bidirectional antenna for universal UHF-RFID applications. The proposed folded antenna comprises upper-layer conductor, lower-layer conductor, and wall patches. The upper-layer conductor consists of two diagonally aligned rectangular plates with a feeding gap at the center, and the lower-layer conductor is of two diagonally adjoined rectangular plates. The upper- and lower-layer conductors are adjoined with the wall patches. Air is used as the substrate to achieve high gain, broad bandwidth, and low cost.
The proposed broadband CP bidirectional antenna was fabricated from copper sheet of $1 \mathrm{~mm}$ in thickness. The selected copper thickness $(1 \mathrm{~mm})$ helped strengthen the antenna structure. The dimension of the proposed antenna was $146 \mathrm{~mm} \times 275 \mathrm{~mm} \times 10 \mathrm{~mm}(W \times L \times h)$. The antenna was excited by a $50 \Omega$ coaxial feed. The width $\left(W_{\mathrm{tf}}\right)$ and length $\left(L_{\mathrm{ty}}\right)$ of the upper-layer rectangular patch were 74 and $138 \mathrm{~mm}$, and the width $\left(W_{\mathrm{bf}}\right)$ and length $\left(L_{\mathrm{by}}\right)$ of the lowerlayer rectangular patch were 74 and $137.5 \mathrm{~mm}$. The upperand lower-layer rectangular patches were staggered by $1 \mathrm{~mm}$. The feeding gap $(\delta)$ was $3 \mathrm{~mm}$ fed by a coaxial cable. An N-type connector was connected to the coaxial cable hidden beneath the upper-layer plate. Table 1 tabulates the antenna parameters and optimal dimensions of the proposed broadband CP bidirectional antenna simulated by CST Microwave Studio [15].

\section{Parametric Study Analysis}

3.1. Evolutionary Stages of the Antenna. Figure 2 shows three evolutionary stages of the proposed antenna: two diagonally aligned rectangular plates (upper-layer plates), the diagonally aligned rectangular plates with wall patches, and broadband CP bidirectional antenna. The initial length of the proposed antenna $(L)$ was approximately $\lambda / 4$ in order to achieve $A R<3 d B$, where $\lambda$ is the wavelength of the center frequency $(900 \mathrm{MHz})$. The optimal length of the antenna was $275 \mathrm{~mm}$. The wall patch dimension and feeding gap were optimized (Table 1). Circular polarization was thus realized as current flowed from the upper-layer plates to the wall patches and to the lower-layer plates. The time $(t)$ for the current to flow from one end to the other end of the wall patch was different, with $90^{\circ}$ phase difference.

Figures 3(a)-3(c) show the simulated $\left|S_{11}\right|$, impedance, and AR pattern of the proposed antenna in the three evolutionary stages. The double-layered structure of the proposed antenna resulted in AR bandwidth lower than $3 \mathrm{~dB}$ for the universal UHF-RFID frequency band. In Figure 3, Stage 1 of the antenna evolution achieved AR bandwidth close to $3 \mathrm{~dB}$, and resistance and reactance were reduced by using the wall patches in Stage 2. In Stage 3, the resistance, reactance, and AR bandwidth were further reduced by incorporating the lower-layer rectangular plates.

3.2. Width of the Proposed Antenna (W). Figures 4(a) and 4(b) show the simulated $\left|S_{11}\right|$ and AR of the proposed antenna under different antenna widths $(W)$ : 140, 143, 146, 149 , and $152 \mathrm{~mm}$. The simulation results revealed that the variation in $W$ had minimal impact on $\left|S_{11}\right|$ but significant effect on AR bandwidth, especially in higher-frequency range. The AR bandwidth became narrower as $W$ increased.

Specifically, as $W$ decreased, the impedance bandwidth $\left(\left|S_{11}\right|<-10 \mathrm{~dB}\right)$ became wider, and AR amplitude deteriorated. On the other hand, as $W$ increased, the impedance bandwidth shifted to lower frequency and became narrower, and AR amplitude deteriorated. The AR bandwidth nonetheless covered the universal UHF-RFID frequency band, independent of $W$. 


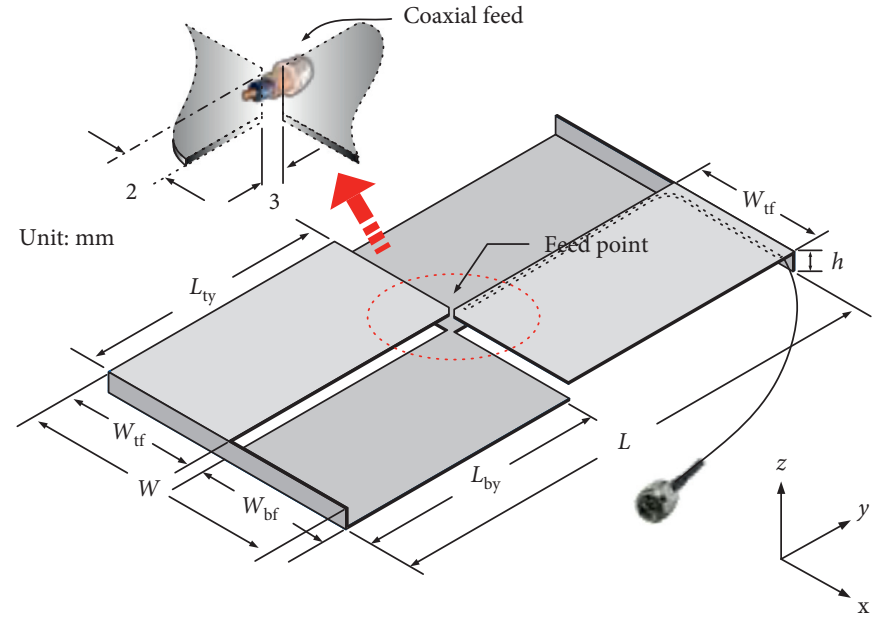

(a)

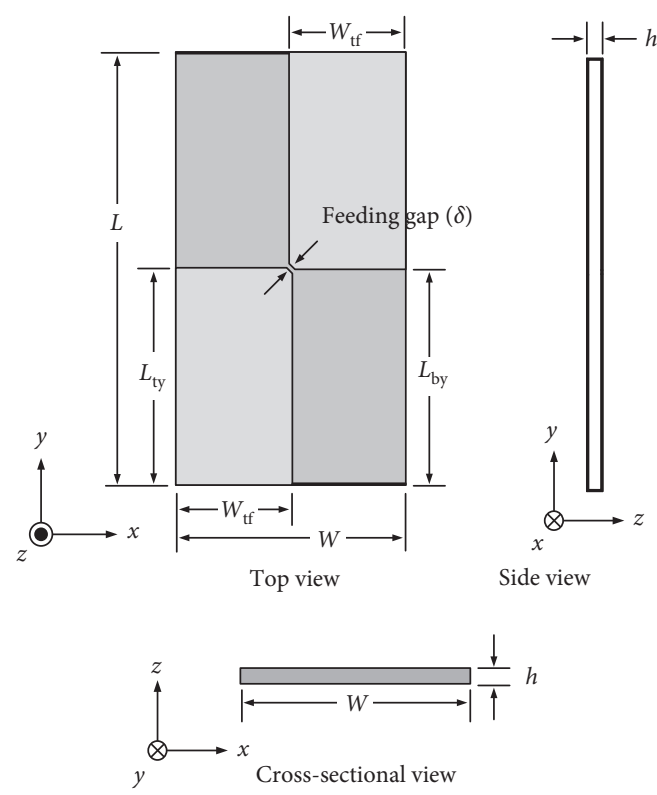

(b)

Figure 1: The geometry of the proposed broadband CP bidirectional antenna. (a) Perspective view, (b) multiview rendition.

TABLE 1: Parameters of single-fed broadband circularly polarized bidirectional antenna operable at universal UHF-RFID frequency band.

\begin{tabular}{lcc}
\hline Symbol & Parameters & $\begin{array}{c}\text { Optimal } \\
\text { dimension }(\mathrm{mm})\end{array}$ \\
\hline$W$ & Width of antenna & 146 \\
$L$ & Length of antenna & 275 \\
$H$ & Height of wall patch & 10 \\
$W_{\mathrm{tf}}$ & Width of upper rectangular patch & 74 \\
$W_{\mathrm{bf}}$ & Width of lower rectangular patch & 74 \\
$L_{\mathrm{ty}}$ & Length of upper rectangular patch & 138 \\
$L_{\mathrm{by}}$ & Length of lower rectangular patch & 137.5 \\
$\Delta$ & Feeding gap & 3 \\
- & Copper thickness & 1 \\
\hline
\end{tabular}

The optimal width $(W)$ of the proposed antenna was $146 \mathrm{~mm}$, given that the AR bandwidth effectively covered the entire UHF-RFID frequency band. Besides, variations in $W$ had no effect on the antenna gain in the lower frequency range and minimal effect in the upper frequency range. As a result, no graphical presentation of the effect of $W$ on the antenna gain was provided.

3.3. Length of Proposed Antenna (L). Figures 5(a) and 5(b) show the simulated $\left|S_{11}\right|$ and AR of the proposed antenna under variable antenna lengths $(L): 265,270,275,280$, and $285 \mathrm{~mm}$. Given the optimal antenna length $(L)$ of $275 \mathrm{~mm}$, as $L$ increased ( 280 and $285 \mathrm{~mm}$ ), the AR bandwidth of the antenna deteriorated and became wider. As $L$ decreased (265 and $270 \mathrm{~mm}$ ), the AR bandwidth became narrower. Meanwhile, as $L$ decreased, the impedance bandwidth $\left(\left|S_{11}\right|\right.$ $<-10 \mathrm{~dB}$ ) shifted to the higher-frequency range with slightly improved antenna gain. As $L$ increased, the impedance bandwidth deteriorated with slightly lower antenna gain. Since variations in $L$ had negligible effect on the antenna gain, no graphical presentation of the effect of $L$ on the antenna gain was provided.

3.4. Height of Wall Patch (h). Figures 6(a) and 6(b) illustrate the simulated $\left|S_{11}\right|$ and AR of the proposed antenna under variable wall heights $(h): 6,8,10,12$, and $14 \mathrm{~mm}$. Given the optimal wall height of $10 \mathrm{~mm}$ (Table 1 ), as $h$ increased (12 and $14 \mathrm{~mm}$ ), the AR bandwidth of the antenna improved and became narrower. As $h$ decreased ( 6 and $8 \mathrm{~mm}$ ), the AR bandwidth became wider. In addition, as $h$ increased $(12 \mathrm{~mm})$, the impedance bandwidth $\left(\left|S_{11}\right|<-10 \mathrm{~dB}\right)$ slightly shifted at the same frequency range with steady antenna gain. As $h$ varied $(6,8$, and $14 \mathrm{~mm}$ ), the impedance bandwidth deteriorated with slightly lower antenna gain. Since variations in $h$ had negligible effect on the antenna gain, no graphical presentation of the effect of $h$ on the antenna gain was provided.

3.5. Length of Feeding Gap $(\delta)$. Given the optimal feeding gap $(\delta)$ at the center of the upper-layer conductor of $3 \mathrm{~mm}$ (Table 1), the simulated impedance bandwidth $\left(\left|S_{11}\right|\right.$ $<-10 \mathrm{~dB})$ covered the universal UHF-RFID frequency band, as shown in Figure 7(a). Figures 7(a) and 7(b) illustrate the simulated $\left|S_{11}\right|$ and AR of the proposed antenna under variable feeding gaps $(\delta): 1,3,5,7$, and $9 \mathrm{~mm}$. In Figure $7(\mathrm{a})$, as $\delta$ increased $(5,7$, and $9 \mathrm{~mm})$, the impedance bandwidth shifted to the lower frequency range, and the impedance bandwidth shifted to the higherfrequency range as $\delta$ decreased $(1 \mathrm{~mm})$. Nonetheless, the AR bandwidth was below $3 \mathrm{~dB}$, independent of $\delta$, as shown in Figure 7(b). 


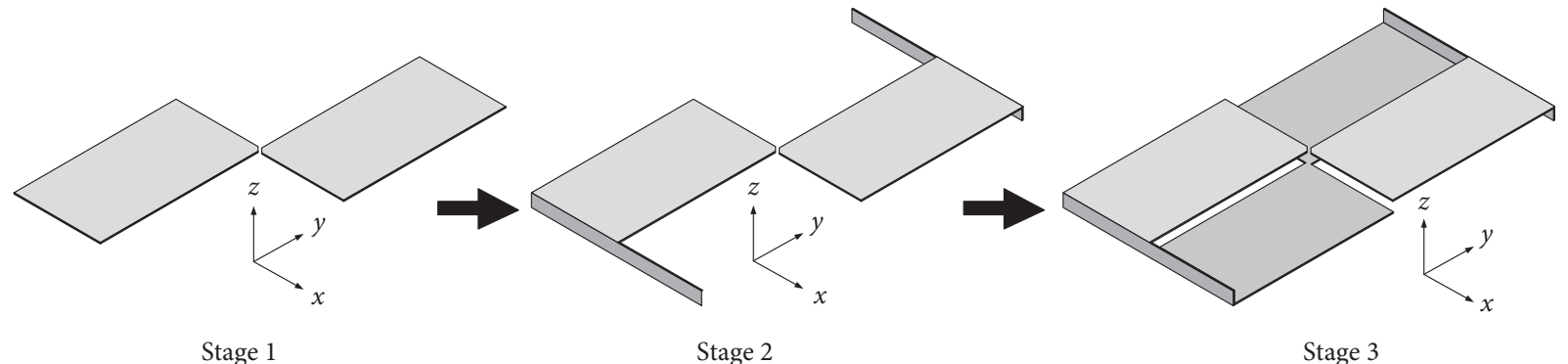

FIGURE 2: Evolutionary stages of the broadband CP bidirectional antenna.

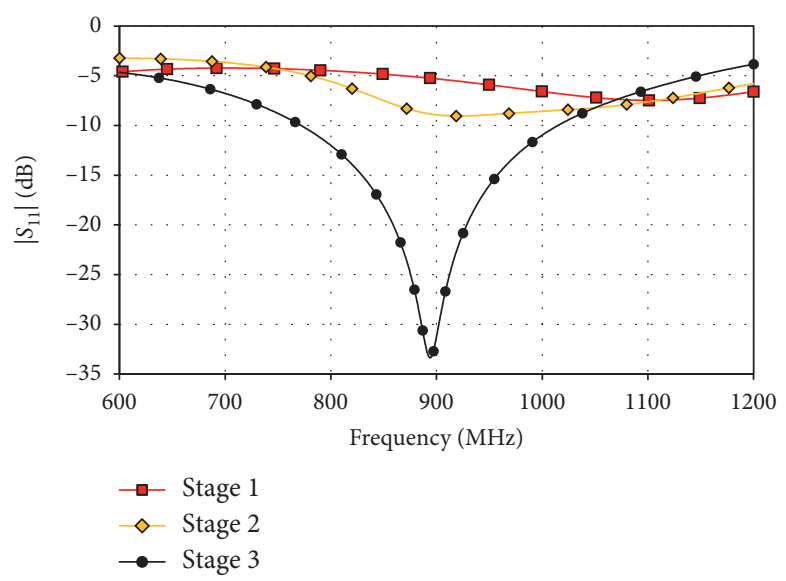

(a)

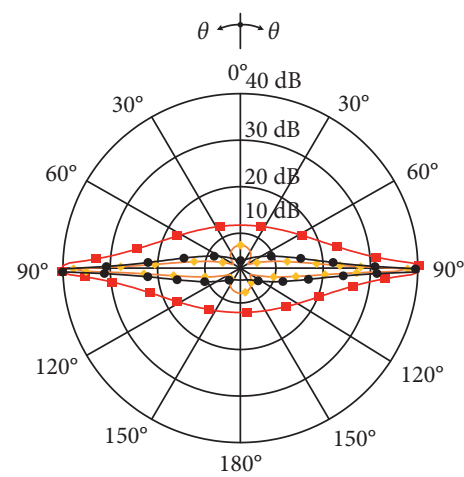

$840 \mathrm{MHz}$

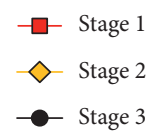

1

age 2

Stage 3

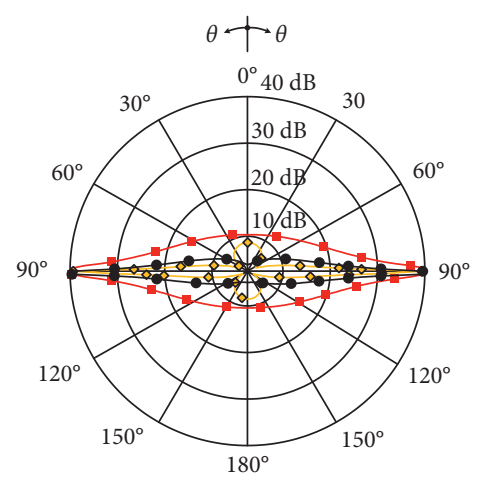

$900 \mathrm{MHz}$

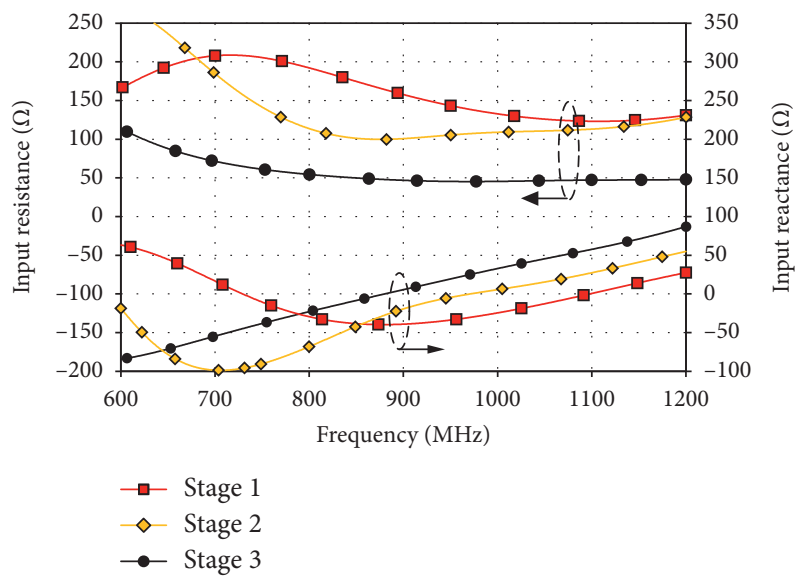

(b)

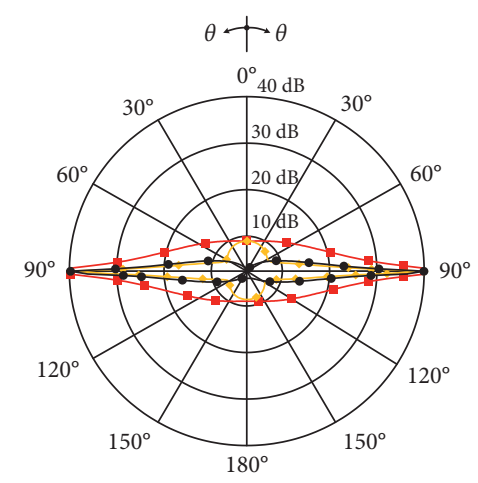

$960 \mathrm{MHz}$

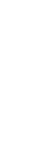




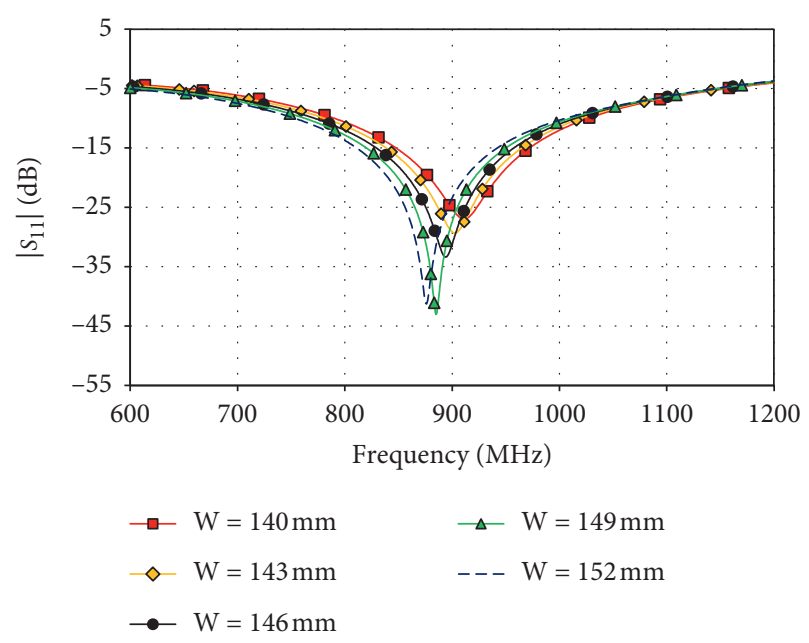

(a)

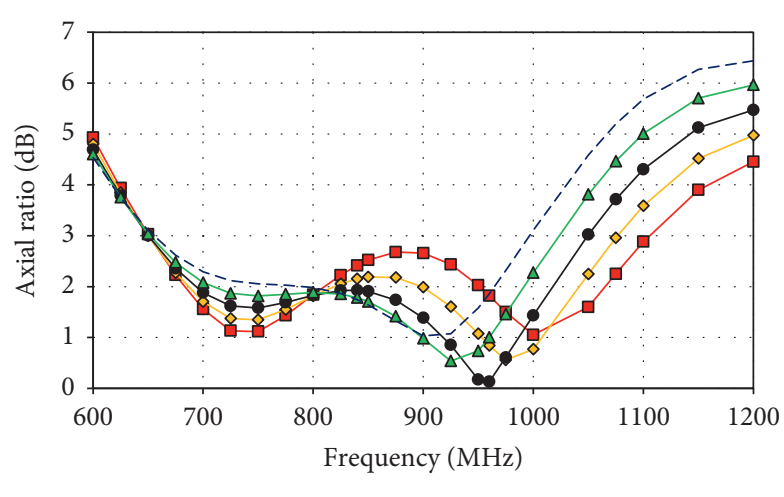

$\begin{array}{ll}\rightarrow \mathrm{W}=140 \mathrm{~mm} & \triangle \mathrm{W}=149 \mathrm{~mm} \\ \diamond \mathrm{W}=143 \mathrm{~mm} & --\mathrm{W}=152 \mathrm{~mm} \\ \multimap \mathrm{W}=146 \mathrm{~mm} & \end{array}$

(b)

FIgURE 4: Simulation results under variable antenna widths (W): (a) $\left|S_{11}\right|$, (b) axial ratio.

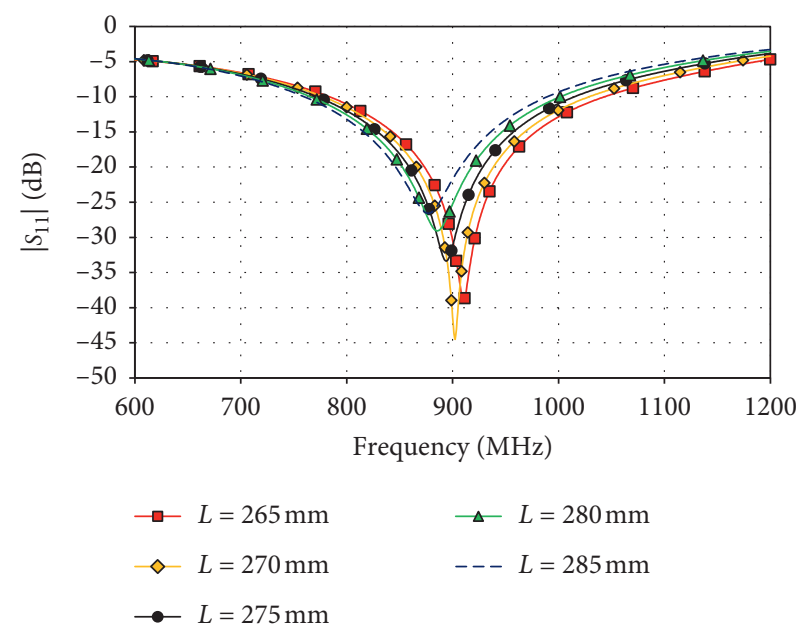

(a)

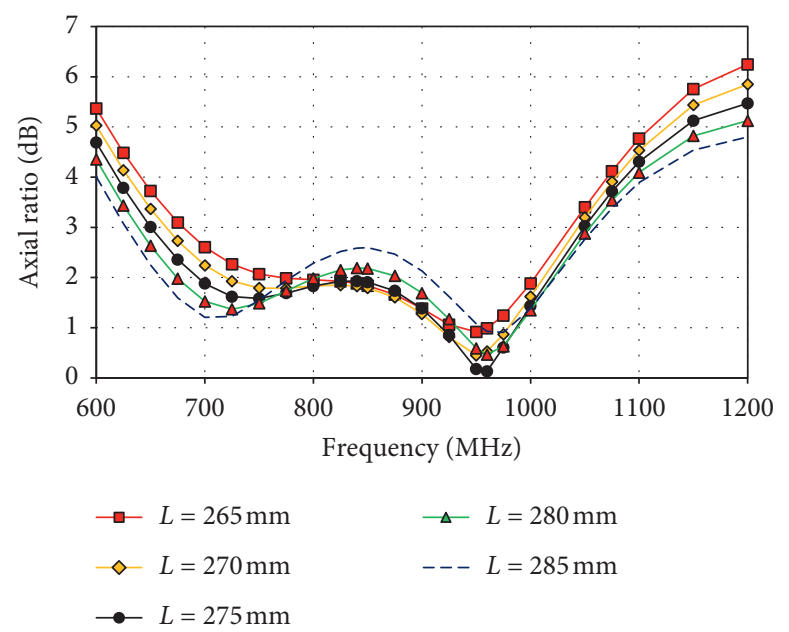

(b)

FIGURE 5: Simulation results under variable antenna lengths $(L)$ : (a) $\left|S_{11}\right|$, (b) axial ratio.

3.7. The Width of Lower Rectangular Plate $\left(W_{b f}\right)$. Figures 9(a) and 9(b) illustrate the simulated $\left|S_{11}\right|$ and AR of the proposed antenna under variable widths of lower rectangular plate $\left(W_{\mathrm{bf}}\right): 34,54,74,94$, and $114 \mathrm{~mm}$. Given the optimal width of lower rectangular patch $\left(W_{\mathrm{bf}}\right)$ of $74 \mathrm{~mm}$ (Table 1$)$, the simulated impedance bandwidth $\left(\left|S_{11}\right|<-10 \mathrm{~dB}\right)$ covered the universal UHF-RFID frequency band, as shown in Figure 9(a). The simulated impedance bandwidth outside of the optimal $W_{\mathrm{bf}}$ $(34,54,94$, and $114 \mathrm{~mm})$ shifted to the lower frequency range, while the AR bandwidth deteriorated and became greater than $3 \mathrm{~dB}$, thereby failing to achieve circular polarization, as shown in Figures 9(a) and 9(b).
3.8. The Length of Upper Rectangular Patch $\left(L_{t y}\right)$. The length of upper rectangular patch $\left(L_{\mathrm{ty}}\right)$ was optimized to improve the AR bandwidth to cover the universal UHFRFID frequency band. Figures 10 (a) and 10(b) illustrate the simulated $\left|S_{11}\right|$ and AR of the proposed antenna under variable lengths of upper rectangular patch $\left(L_{\mathrm{ty}}\right): 58,95$, 138,178 , and $218 \mathrm{~mm}$. Given the optimal length of upper rectangular patch $\left(L_{\text {ty }}\right)$ of $138 \mathrm{~mm}$ (Table 1 ), the simulated impedance bandwidth $\left(\left|S_{11}\right|<-10 \mathrm{~dB}\right)$ covered the universal UHF-RFID frequency band, as shown in Figure 10(a). Under $L_{\text {ty }}$ of $58,95,178$, and $218 \mathrm{~mm}$, the simulated impedance bandwidth failed to cover the 

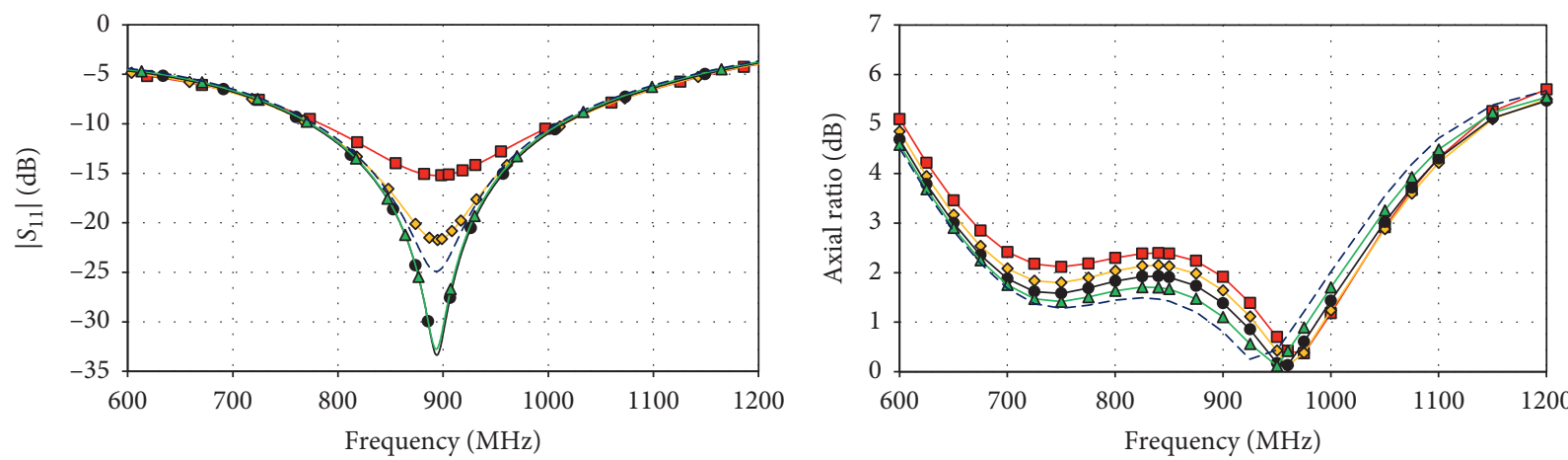

$$
\begin{array}{ll}
\rightarrow h=6 \mathrm{~mm} & \triangle h=12 \mathrm{~mm} \\
\diamond h=8 \mathrm{~mm} & --h=14 \mathrm{~mm} \\
\rightarrow h=10 \mathrm{~mm} &
\end{array}
$$

(a)

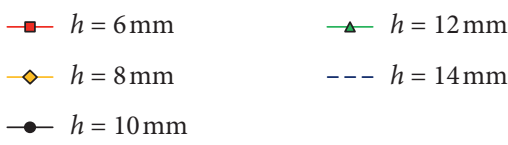

(b)

Figure 6: Simulation results under variable wall heights (h): (a) $\left|S_{11}\right|$, (b) axial ratio.

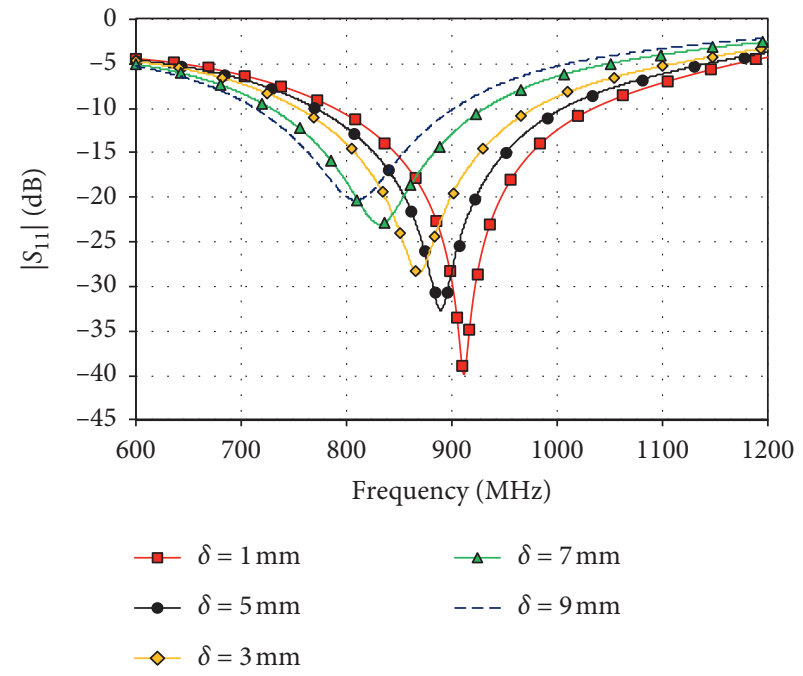

(a)

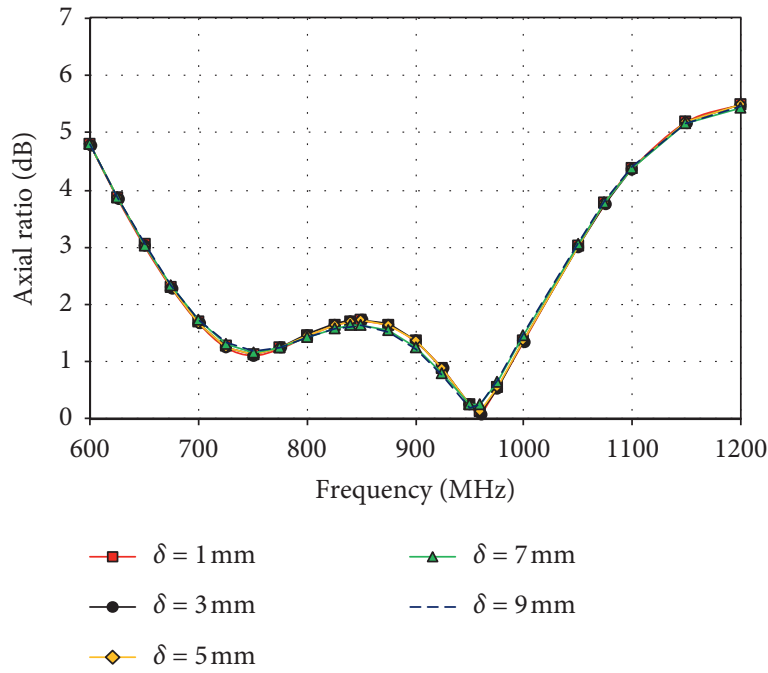

(b)

FIgURE 7: Simulation results under variable feeding gap ( $\delta$ ): (a) $\left|S_{11}\right|$, (b) axial ratio.
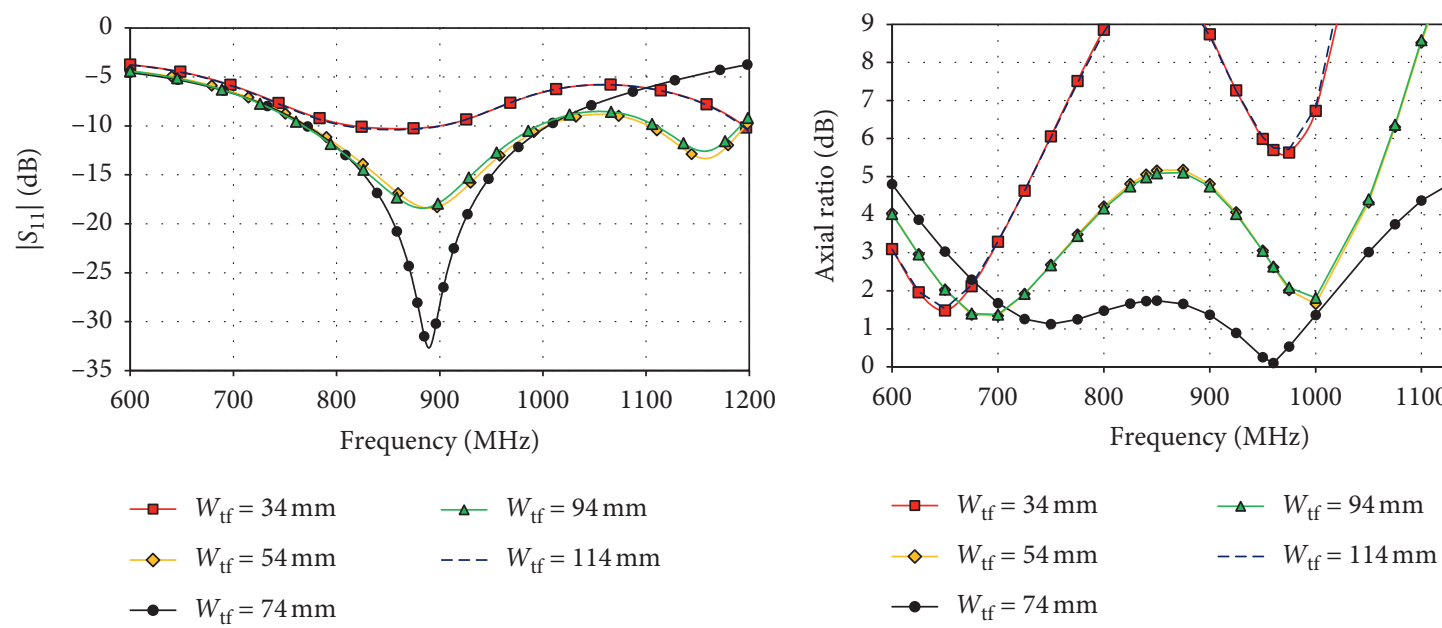

(a)

(b)

FiguRE 8: Simulation results under variable widths of upper rectangular plate $\left((W)_{\mathrm{tf}}\right)$ : (a) $\left|S_{11}\right|$, (b) axial ratio. 


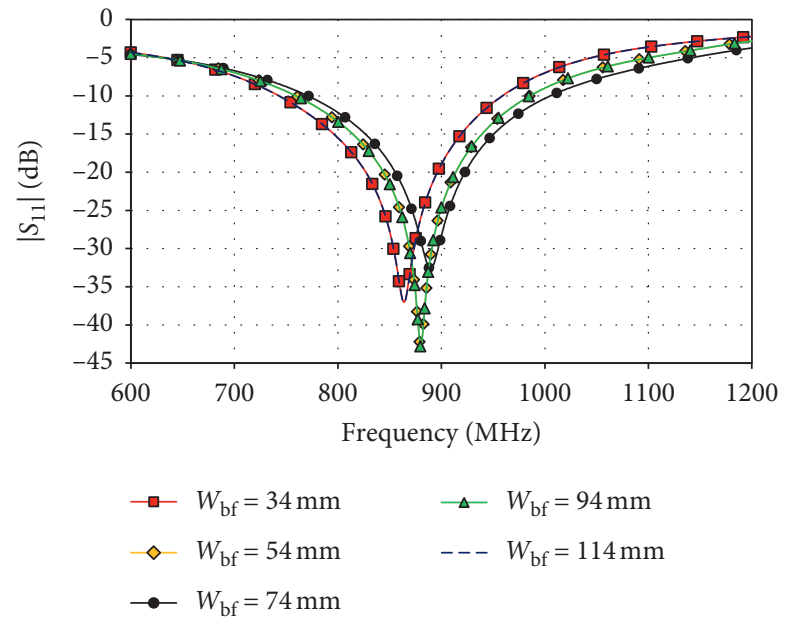

(a)

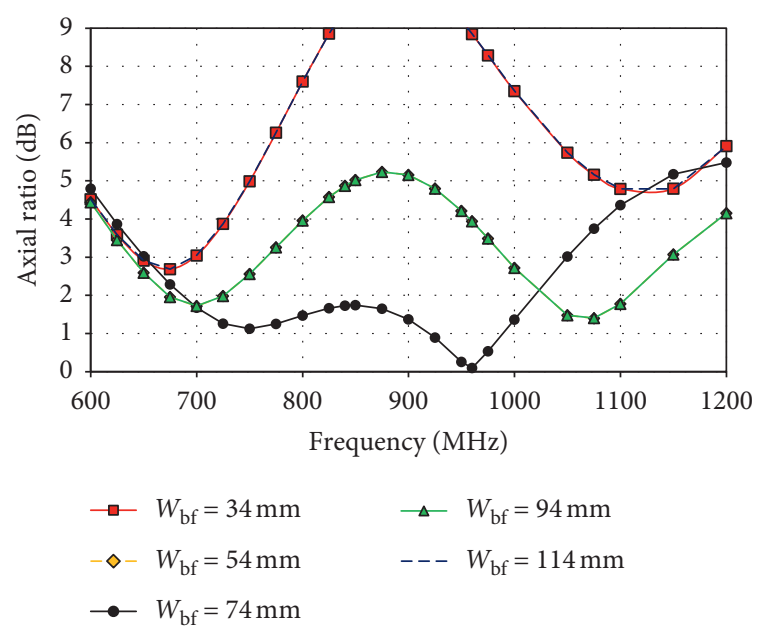

(b)

FIGURE 9: Simulation results under variable widths of lower rectangular plate $\left((W)_{\mathrm{bf}}\right)$ : (a) $\left|S_{11}\right|$, (b) axial ratio.

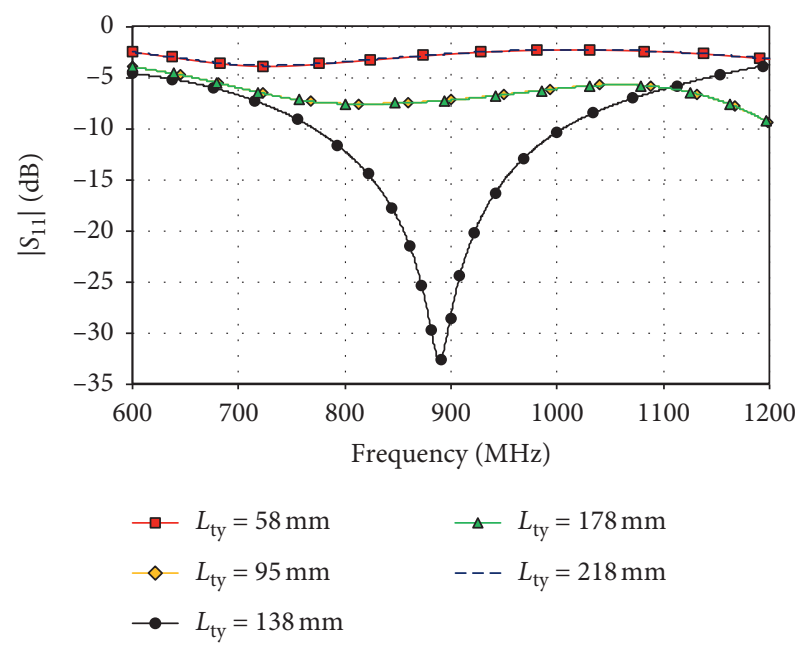

(a)

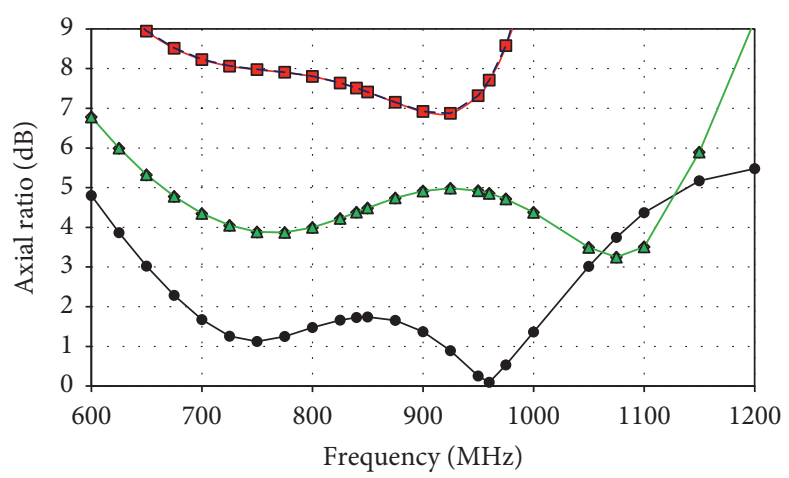

$$
\begin{aligned}
& \rightarrow-L_{\text {ty }}=58 \mathrm{~mm} \\
& \diamond L_{\text {ty }}=95 \mathrm{~mm} \\
& \rightarrow-L_{\text {ty }}=138 \mathrm{~mm}
\end{aligned}
$$

(b)

FiguRE 10: Simulation results under variable lengths of upper rectangular patch $\left((L)_{\text {ty }}\right)$ : (a) $\left|S_{11}\right|$, (b) axial ratio.

universal UHF-RFID frequency band, and the AR bandwidth deteriorated and became greater than $3 \mathrm{~dB}$, thus failing to achieve circular polarization, as shown in Figures 10(a) and 10(b).

3.9. The Length of Lower Rectangular Patch $\left(L_{b y}\right)$. Figures 11(a) and 11(b) show the simulated $\left|S_{11}\right|$ and AR of the proposed antenna under variable lengths of lower rectangular plate $\left(L_{\text {by }}\right): 57.5,94.5,137.5,177.5$, and $217.5 \mathrm{~mm}$. Given the optimal length of lower rectangular patch $\left(L_{\text {by }}\right)$ of $137.5 \mathrm{~mm}$ (Table 1$)$, the simulated impedance bandwidth $\left(\left|S_{11}\right|<-10 \mathrm{~dB}\right)$ covered the universal UHF-RFID frequency band, as shown in Figure 11(a). The simulated impedance bandwidth outside of the optimal $L_{\text {by }}(57.5,94.5$, 177.5 , and $217.5 \mathrm{~mm}$ ) shifted to the lower frequency range and deteriorated, while the AR bandwidth deteriorated and became greater than $3 \mathrm{~dB}$, thus failing to achieve circular polarization, as shown in Figures 11(a) and 11(b).

3.10. Vector Current Distribution on the Upper-Layer Diagonally Aligned Rectangular Plates. Figure 12 illustrates the simulated vector current distribution on the upper-layer diagonally aligned rectangular plates at the center frequency of $900 \mathrm{MHz}$ relative to time $(t)$. The current from the feeding point at the center of the upper-layer plates was distributed on the upper-layer conductor surface with the same magnitude and $90^{\circ}$ phase difference, independent of time $(t)$. The direction of surface current on the upper-layer diagonally aligned rectangular plates was counterclockwise relative to time $(t)$. Meanwhile, the surface current on the lower-layer diagonally adjoined rectangular plates was clockwise relative to time $(t)$. The directions of surface current on the upper- and lower- 

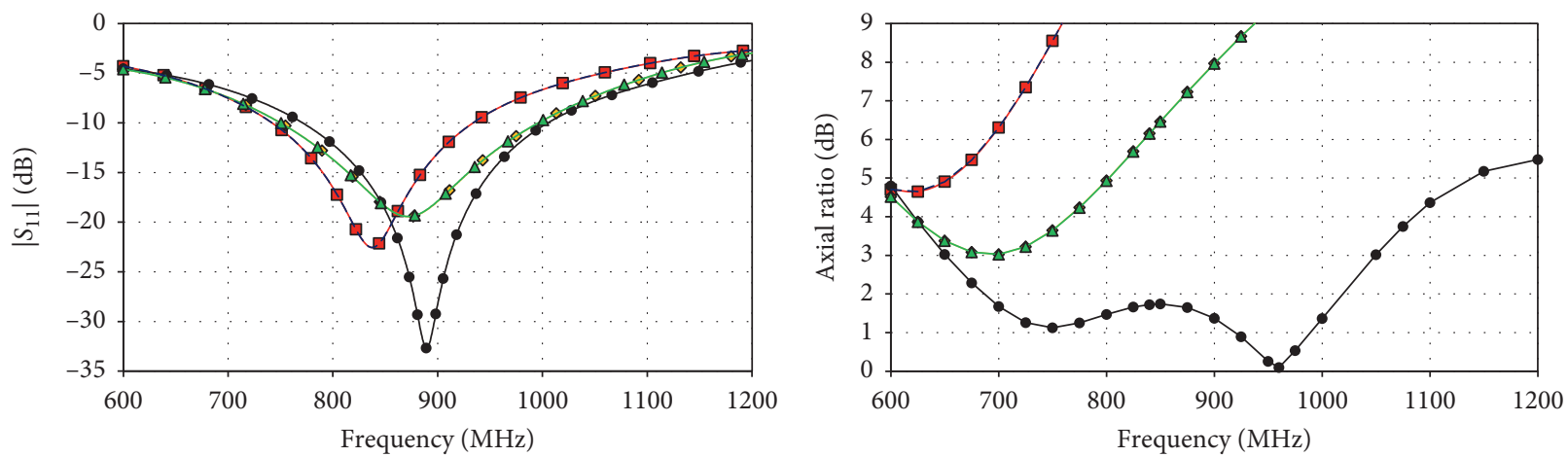

$$
\begin{aligned}
& \rightarrow L_{\mathrm{by}}=57.5 \mathrm{~mm} \\
& \diamond L_{\mathrm{by}}=97.5 \mathrm{~mm} \\
& \rightarrow-L_{\mathrm{by}}=137.5 \mathrm{~mm}
\end{aligned}
$$

(a)

$$
\begin{aligned}
& \longrightarrow L_{\text {by }}=57.5 \mathrm{~mm} \\
& \diamond L_{\text {by }}=97.5 \mathrm{~mm} \\
& \rightarrow L_{\text {by }}=137.5 \mathrm{~mm}
\end{aligned}
$$

(b)

FIGURE 11: Simulation results under variable lengths of lower rectangular patch $\left(L_{\text {by }}\right)$ : (a) $\left|S_{11}\right|$, (b) axial ratio.
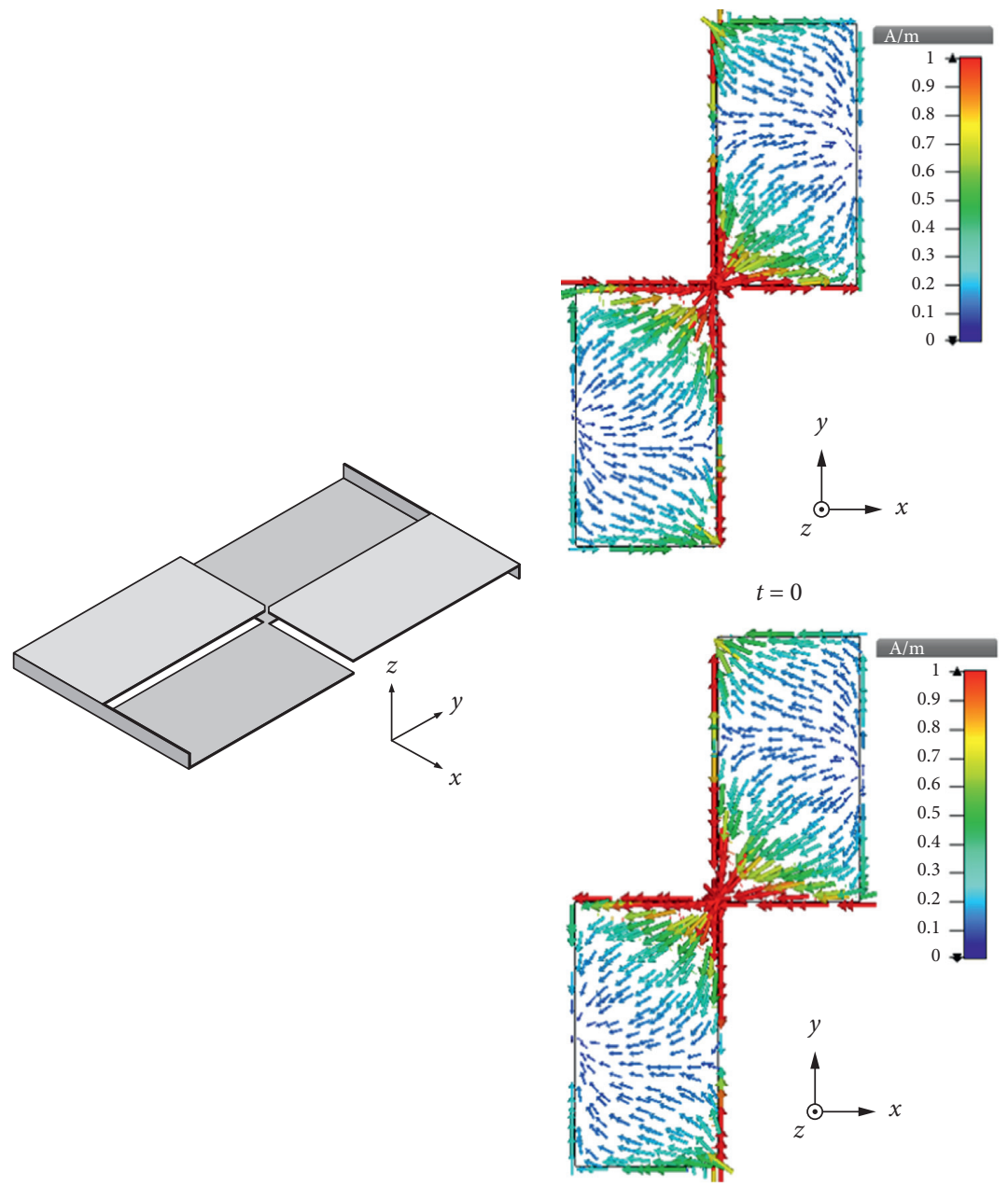

$t=T / 2$
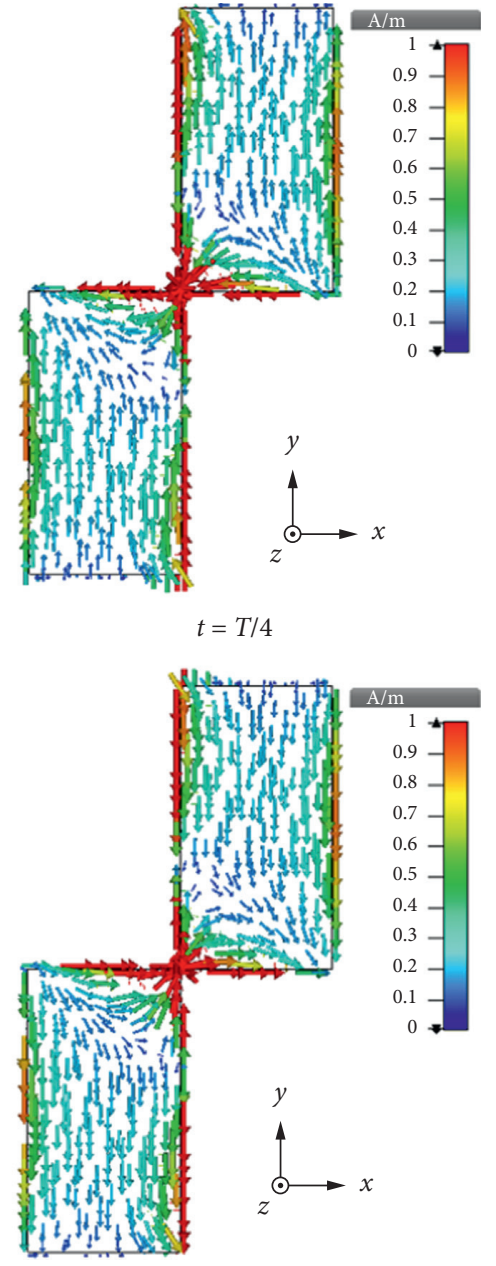

$t=3 T / 4$

FIGURE 12: Simulated vector current distribution on the upper-layer diagonally aligned rectangular plates at the center frequency of $900 \mathrm{MHz}$. 


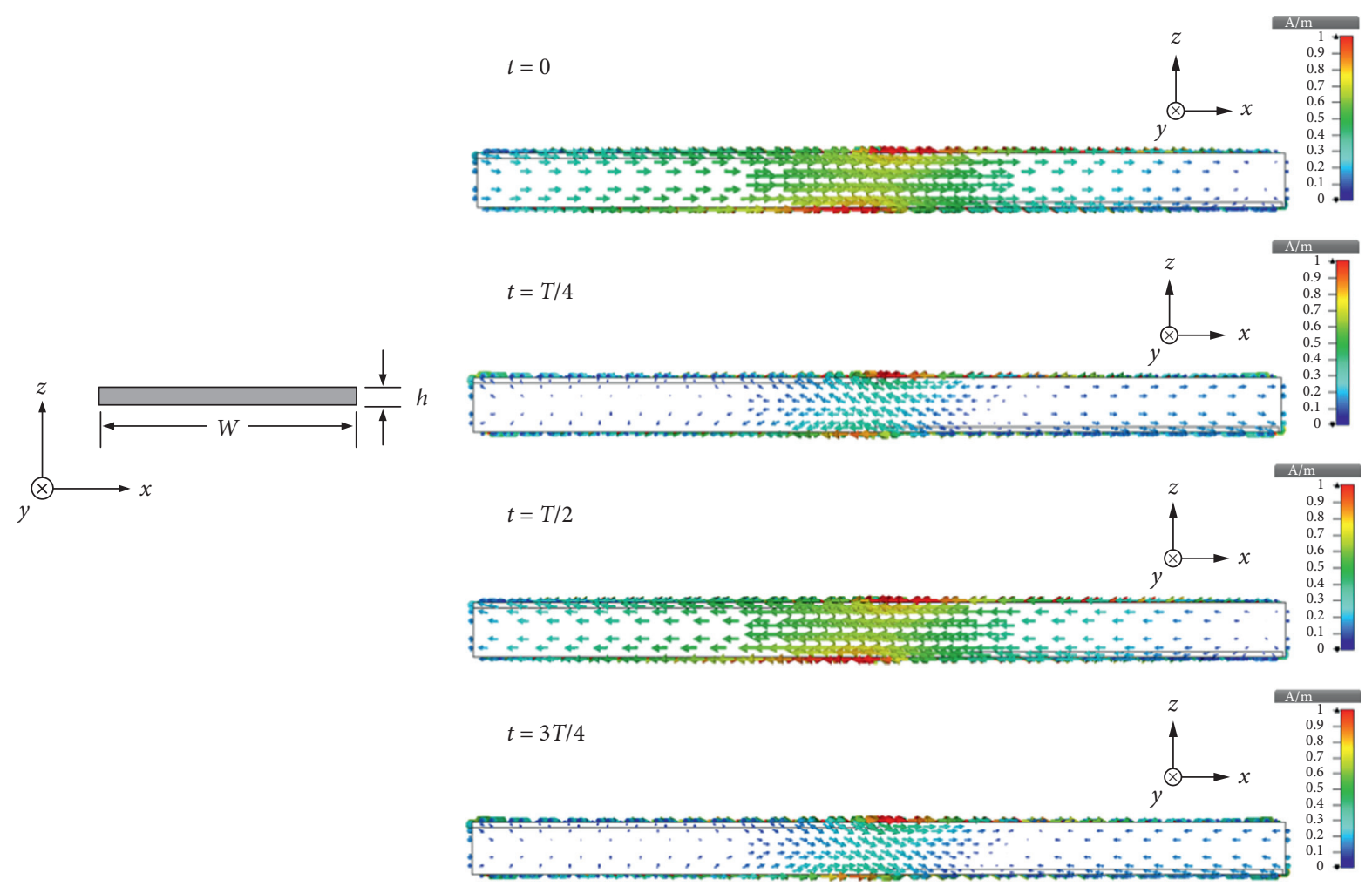

FIGURE 13: Simulated vector current distribution on one end of the wall patch at the center frequency of $900 \mathrm{MHz}$.

layer rectangular plates at 840 and $960 \mathrm{MHz}$ resembled those at the center frequency. The concurrent use of upper- and lower-layer diagonally aligned rectangular plates thus resulted in circular polarization.

Figure 13 shows the simulated current distribution on one end of the wall patch at the center frequency of $900 \mathrm{MHz}$ relative to time $(t)$. The direction of surface current was counterclockwise, while that of the other end of the wall patch was clockwise. The opposite directions of surface current resulted in circular polarization. The directions of surface current on the both ends of the wall patch at 840 and $960 \mathrm{MHz}$ resembled those at the center frequency.

\section{Simulation and Measurement Results}

A prototype antenna was fabricated based on the optimal dimensions (Table 1), and far-field experiments were carried out in an anechoic chamber using HP8720C network analyzer. Figure 14 depicts the prototype broadband CP bidirectional antenna.

Figure 15(a) illustrates the simulated and measured $\left|S_{11}\right|$ of the broadband CP bidirectional antenna. The simulated and measured $\left|S_{11}\right|(\leq-10 \mathrm{~dB})$ covered the frequency range of $772.19-1014.6 \mathrm{MHz}(27.13 \%$ bandwidth $)$ and $759-1011 \mathrm{MHz}$ (28.47\% bandwidth), respectively, both of which encompassed the universal UHF-RFID frequency band of $840-960 \mathrm{MHz}$. The simulated and measured results were in good agreement. In Figure 15(b), the simulated and measured 3-dB AR bandwidth of the proposed antenna were $675-1000 \mathrm{MHz}(38.80 \% \mathrm{AR}$

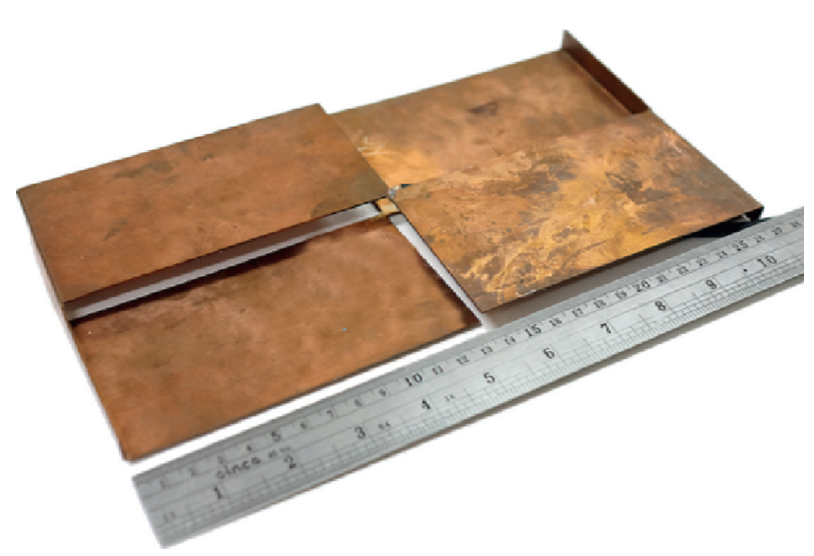

FIgURE 14: Photograph of the prototype broadband CP bidirectional antenna.

bandwidth) and $648-1110 \mathrm{MHz}$ (52.55\% AR bandwidth), respectively.

Figures 16(a)-16(c) show the simulated and measured $x-z$ and $y-z$ plane radiation patterns at 840,900 (center frequency), and $960 \mathrm{MHz}$, respectively. The total radiation patterns were bidirectional in both planes with circular polarization. The radiation patterns were near-symmetrical in front-back boresight for the universal UHF-RFID frequency band. The CP pattern is LHCP in direction of $180^{\circ}$ along the operating frequency band. The simulated LHCP half-power beamwidth (HPBW) in $x-z$ and $y-z$ planes at 840,900 , and 


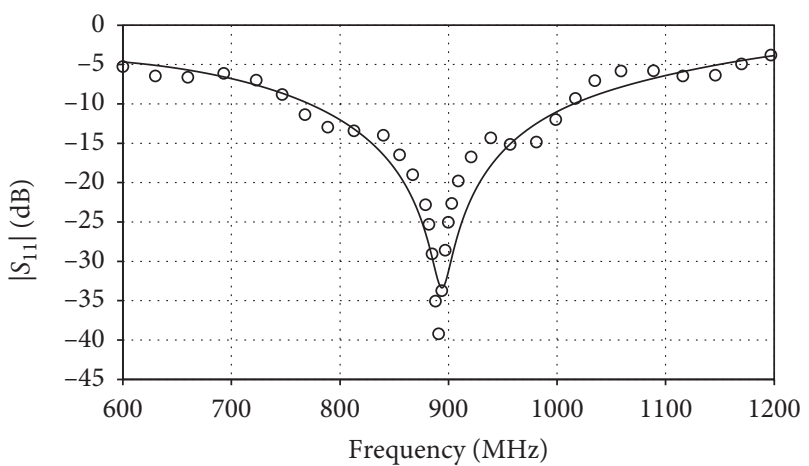

— Simulated oo० Measured

(a)

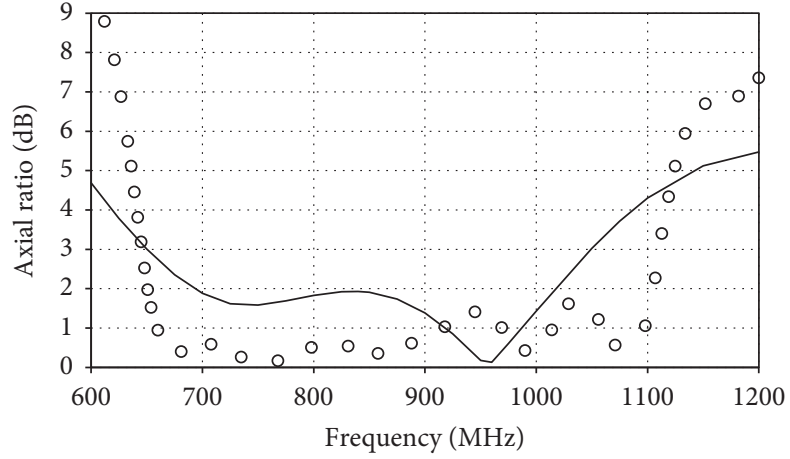

— Simulated

০০০ Measured

Figure 15: Simulated and measured results of the proposed antenna: (a) $\left|S_{11}\right|$, (b) axial ratio.
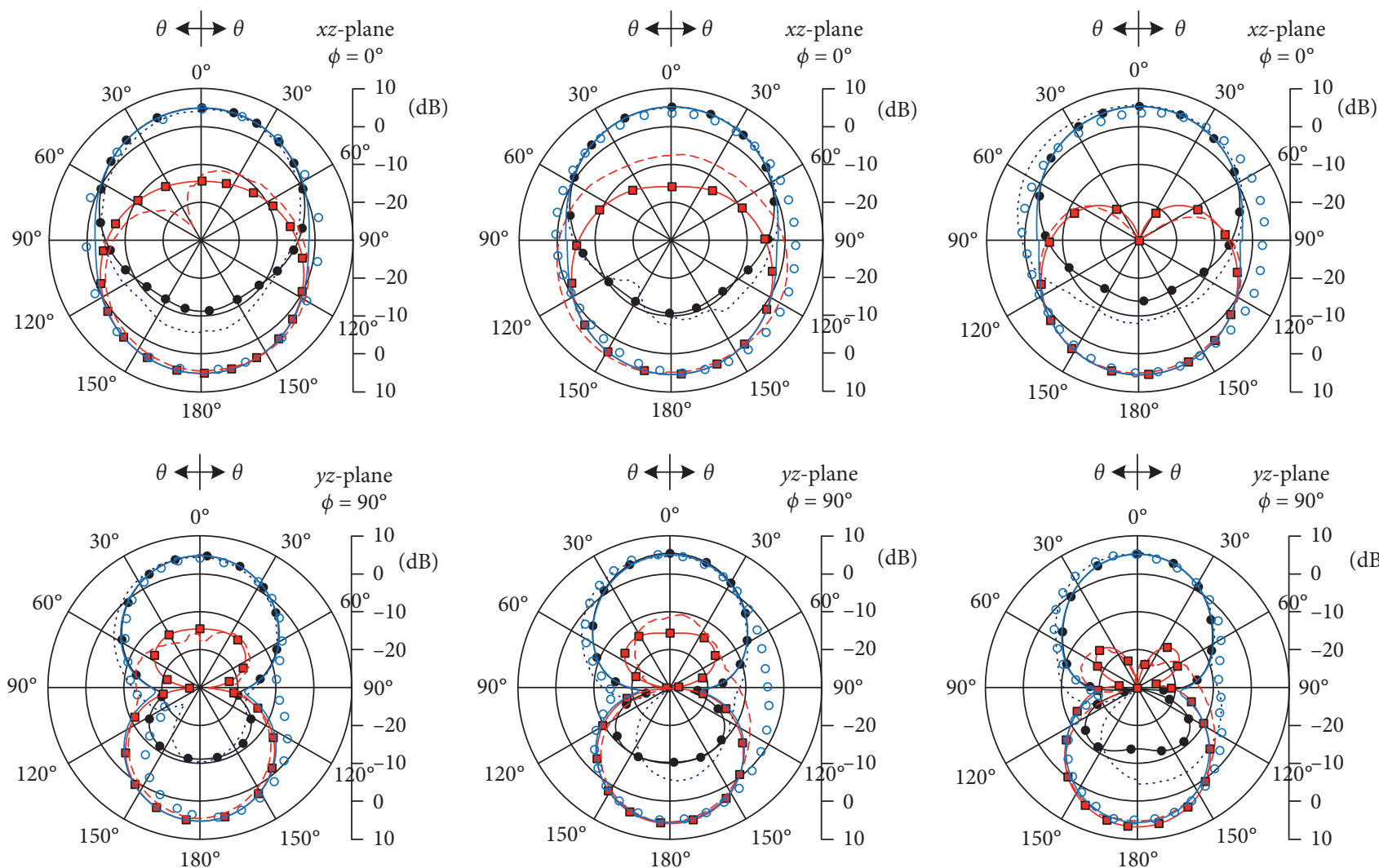

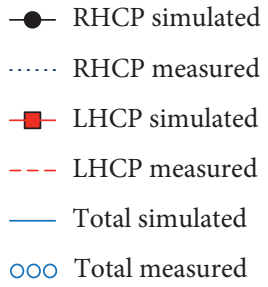

(a)

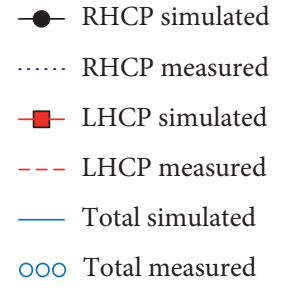

(b)

(b) 


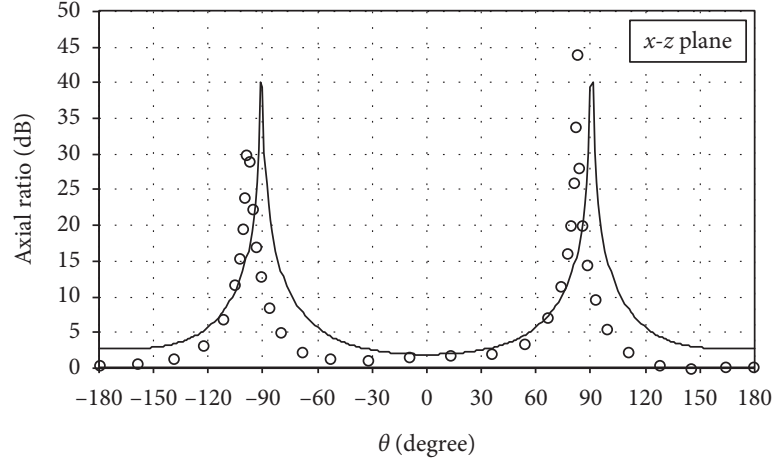

— Simulated

ooo Measured

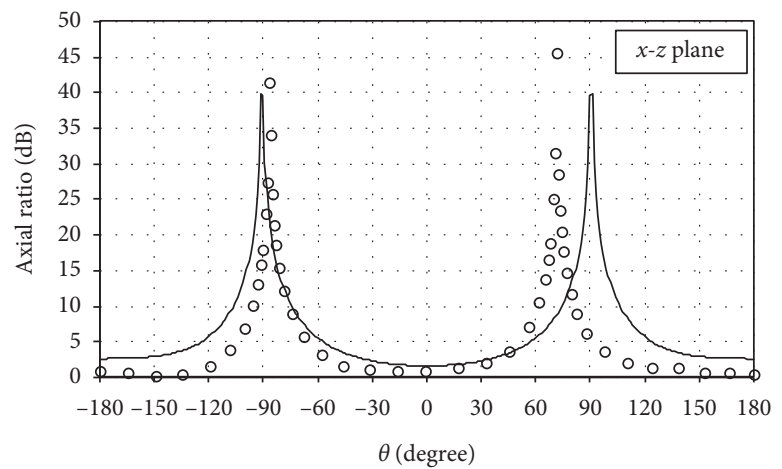

__ Simulated

ooo Measured

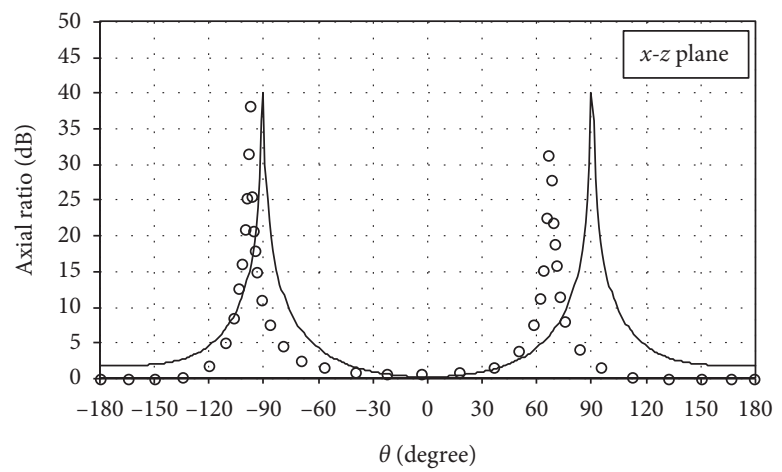

— Simulated

ooo Measured

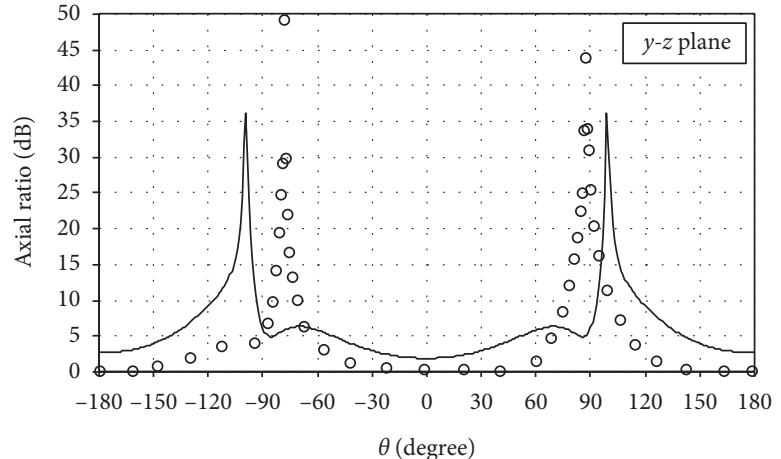

_ Simulated

ooo Measured

(a)

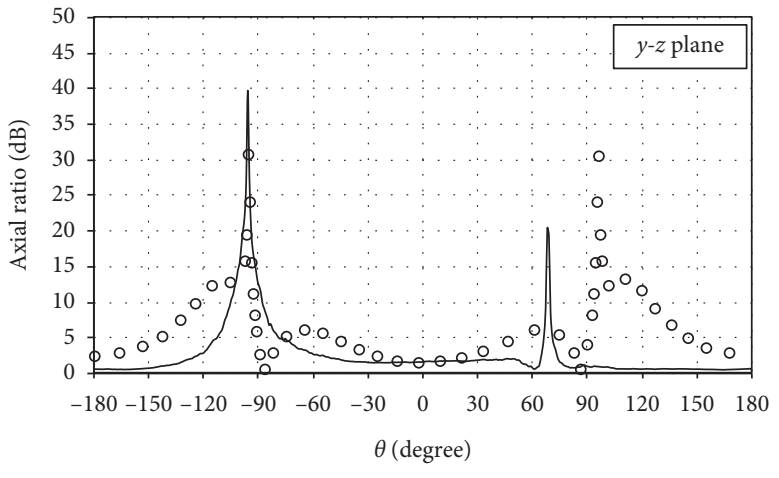

_ Simulated

o०० Measured

(b)

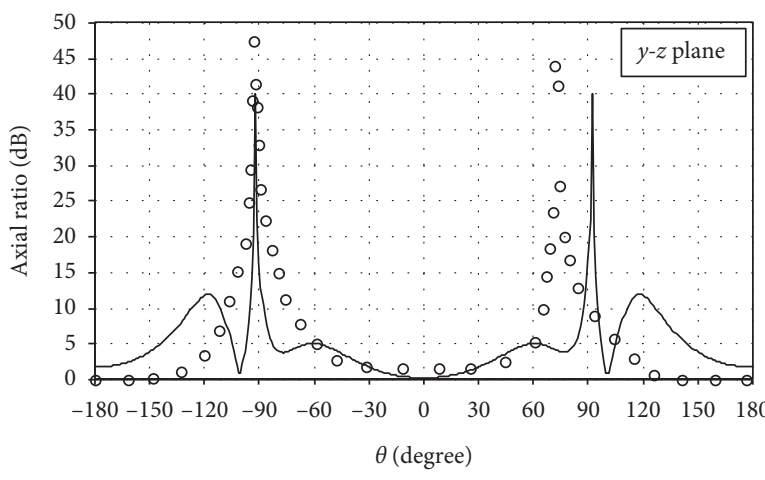

— Simulated

ooo Measured

(c)

FIGURE 17: Simulated and measured $x z$ and $y z$ plane axial ratio relative to angle. (a) $840 \mathrm{MHz}$, (b) $900 \mathrm{MHz}$, (c) $960 \mathrm{MHz}$.

$960 \mathrm{MHz}$ was $90^{\circ}$ and $56^{\circ} ; 86^{\circ}$ and $56^{\circ}$; and $82^{\circ}$ and $56^{\circ}$. The corresponding measured LHCP HPBW were $98^{\circ}$ and $52^{\circ} ; 97^{\circ}$ and $52^{\circ}$; and $88^{\circ}$ and $56^{\circ}$. The RHCP pattern occurred in direction of $0^{\circ}$. The RHCP HPBW in $x-z$ and $y-z$ planes at 840,900 , and $960 \mathrm{MHz}$ were $92^{\circ}$ and $56^{\circ} ; 84^{\circ}$ and $54^{\circ}$; and $76^{\circ}$ and $54^{\circ}$. The corresponding measured RHCP HPBW were $79^{\circ}$ and $62^{\circ} ; 97^{\circ}$ and $63^{\circ}$; and $88^{\circ}$ and $65^{\circ}$.
The simulated $x z$ and $y z$ plane 3 -dB AR beamwidth at 840 , 900 , and $960 \mathrm{MHz}$ was $76^{\circ}$ and $60^{\circ} ; 80^{\circ}$ and $62^{\circ}$; and $104^{\circ}$ and $80^{\circ}$. The corresponding measured $3-\mathrm{dB}$ AR beamwidth was $123^{\circ}$ and $118^{\circ} ; 96^{\circ}$ and $126^{\circ}$; and $117^{\circ}$ and $97^{\circ}$, as shown in Figures 17(a)-17(c), respectively.

Figure 18 compares the simulated and measured realized gains of the proposed broadband CP bidirectional antenna. The 


\section{Comparison between $\mathrm{CP}$ Bidirectional Antennas}

The overall dimension of the proposed single-fed broadband $\mathrm{CP}$ bidirectional antenna is $146 \mathrm{~mm} \times 275 \mathrm{~mm} \times 10 \mathrm{~mm}$ excluding the coaxial cable and N-type connector. The coaxial cable and the connector were required to feed radio frequency (RF) signal to the upper-layer diagonally aligned rectangular plates, and the length of the coaxial cable was $\lambda / 4$ at the center frequency.

Table 3 compares the proposed broadband CP bidirectional antenna with existing $\mathrm{CP}$ bidirectional antennas. In $[6,12]$, the higher-frequency antennas achieved improved impedance and AR bandwidths but lower antenna gain. In [7], the antenna achieved higher gain but narrower impedance and $\mathrm{AR}$ bandwidths. In $[8,13]$, the antennas were smaller than the proposed antenna but achieved lower antenna gain. In [9], the antenna had narrower AR bandwidth and lower antenna gain. In $[11,14]$, the antennas achieved higher gain but suffered from bulkiness. For antennas operable in the universal UHF-RFID frequency band $(840-960 \mathrm{MHz})$, the proposed single-fed broadband CP bidirectional antenna efficiently achieves high bidirectional antenna gain with compact size.

\section{Conclusions}

This experiment research introduced a technique of diagonal alignment of two rectangular copper plates to generate circular polarization and improve 3-dB AR bandwidth, where the principle of circular polarization is proved by surface current analysis. Moreover, double layers of diagonally aligned rectangular plates were adopted to improve impedance bandwidth $\left(S_{11}\right)$ $<-10 \mathrm{~dB})$ and achieve bidirectional radiation pattern. According to the characteristics that were analyzed and described in detail of the parametric study section, the prototype antenna was fabricated based on the optimal dimensions, and far-field experiments were carried out in an anechoic chamber using HP8720C network analyzer. The impedance bandwidth, 3-dB AR bandwidth, LHCP/ RHCP HPBW, 3-dB AR beamwidth, and gain of the prototype UHF-RFID antenna were $759-1011 \mathrm{MHz}$ $(28.74 \%), \quad 648-1110 \mathrm{MHz}(52.55 \%), 52^{\circ}-98^{\circ} / 62^{\circ}-97^{\circ}$, $96^{\circ}-126^{\circ}$, and $4.28-5.72 \mathrm{dBic}$, respectively. The proposed single-fed broadband CP bidirectional antenna is thus universally applicable to UHF-RFID readers of varying geographical areas.

\section{Data Availability}

The data used to support the findings of this study are available from the corresponding author upon request.

\section{Conflicts of Interest}

The authors declare that there are no conflicts of interest regarding the publication of this paper.

\section{Acknowledgments}

This research was funded by the College of Industrial Technology, King Mongkut's University of Technology North Bangkok with grant no. RES-CIT0321/2018. This work has also been supported by the Thailand Research Fund through the TRF Senior Research Scholar Program with grant no. RTA6080008.

\section{References}

[1] K. Finkenzeller, "RFID Handbook: Fundamentals and Applications in Contactless Smart Cards and Identification," John Wiley and Sons, Ltd., Hoboken, NJ, USA, 2003.

[2] Y. Yao, C. Cui, J. Yu, and X. Chen, "A meander line UHF RFID reader antenna for near-field applications," IEEE Transactions on Antennas and Propagation, vol. 65, no. 1, pp. 82-91, 2017.

[3] R. Colella, L. Catarinucci, A. Michel, and P. Nepa, "Design of a 3D-printed circularly polarized antenna for portable UHF RFID readers," in Proceedings of 2017 IEEE International Conference on RFID Technology \& Application (RFID-TA), pp. 225-228, Warsaw, Poland, September 2017.

[4] S. Fu, C. Li, S. Fang, and Z. Wang, "Low-cost single-fed circularly polarized stacked patch antenna for UHF RFID reader applications," in Proceedings of 2016 Progress in Electromagnetic Research Symposium (PIERS), pp. 2031-2034, Shanghai, China, August 2016.

[5] T. Tipsawate, C. Phongcharoenpanich, and S. Kosulvit, "A wideband bidirectional antenna using truncated circular sector fed by rectangular monopole," in Proceedings of 6 th International Conference on Electrical Engineering/Electronics, Computer, Telecommunications and Information Technology, vol. 2, pp. 782-785, Pattaya, Chonburi, Thailand, January 2009.

[6] J. Y. Sze, C.-I. G. Hsu, Z. W. Chen, and C. C. Chang, "Broadband $\mathrm{CPW}$-fed circularly polarized square slot antenna with lighteningshaped feedline and inverted-L grounded strips," IEEE Transactions on Antennas and Propagation, vol. 58, no. 3, pp. 973-977, 2010.

[7] J.-H. Lu and S.-F. Wang, "Planar broadband circularly polarized antenna with square slot for UHF RFID reader," IEEE Transactions on Antennas and Propagation, vol. 61, no. 1, pp. 45-53, 2013.

[8] R. Cao and S.-C. Yu, "Wideband compact CPW-fed circularly polarized antenna for universal UHF RFID reader," IEEE Transactions on Antennas and Propagation, vol. 63, no. 9, pp. 973-977, 2015.

[9] R. Xu, J.-Y. Li, and J. Liu, "Frequency-selective polarisation antenna based on simple rotational symmetric printed bowtie dipole structure," IET Microwaves, Antennas \& Propagation, vol. 12, no. 7, pp. 1107-1111, 2018.

[10] W.-H. Zhang, W.-J. Lu, and K.-W. Tam, "Circularly polarized complementary antenna with tilted beam based on orthogonal dipoles," IEEE Antennas and Wireless Propagation Letters, vol. 17, no. 8, pp. 1406-1410, 2018.

[11] W.-H. Zhang, W.-J. Lu, and K.-W. Tam, "Design of circularly polarized conical RFID reader antenna based on natural boundary conditions," IEEE Journal of Radio Frequency Identification, vol. 2, no. 2, pp. 104-110, 2018.

[12] U. Ullah and S. Koziel, "A geometrically simple compact wideband circularly polarized antenna," IEEE Antennas and Wireless Propagation Letters, vol. 18, no. 6, pp. 1179-1183, 2019. 
[13] W. Abdelrahim and Q. Feng, "Compact broadband dual-band circularly polarised antenna for universal UHF RFID handheld reader and GPS applications," IET Microwaves, Antennas \& Propagation, vol. 13, no. 10, pp. 1664-1670, 2019.

[14] Y. Pan and Y. Dong, "Low-profile low-cost ultra-wideband circularly polarized slot antennas," IEEE Access, vol. 7, no. 3, pp. 973-977, 2019.

[15] CST Microwave Studio Suite, Computer Simulation Technology, Dassault Systèmes Americas Corp., USA, 2019. 